\title{
輅南鵭礦地質勘探工作中學習蘇聯 先進經驗的幾笘體會
}

\author{
莫柱 孫
}

（中南地賀局，中南地筫㬝探公司）

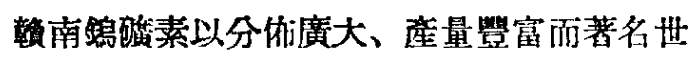
界。在解放以前，帝國主義和國民黨反動政府只

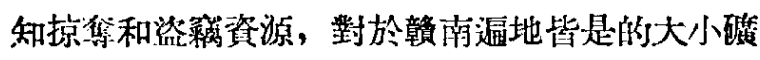

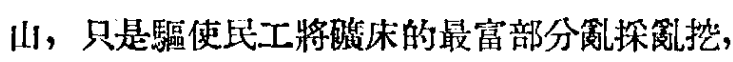
從來没有淮行過正規的地質勘探工作, 更談不上 有系統的開發設計。因此，今日䫓南哓個座量較

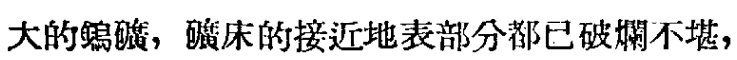

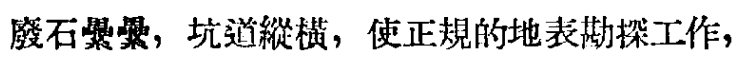
有無從下手之感。今天要想通過地表調查和 觀 察, 去了解磁脉的分倠、產狀和品位, 是一件十 分不容易的事。

隨着忨國大規模經淤建设的開始，䫓南、等

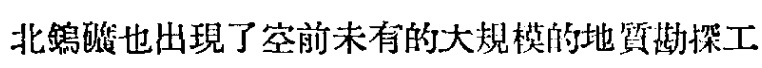
作。赸初，面對看䫓南這些地表上已破爛不进的

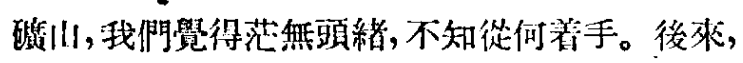
蘇聯專家先後親臨工地, 給予我們具僼的垶助和 指導。在全體工作同志婄真貫徹蘇聯專家建議的 努力下, 各項工作漸入正軌，從而摸到了一些紃

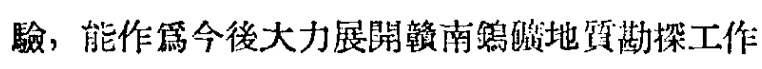
的依據。這些經驗具體地說明了筑萑聯先進經驗的 優越性。現在試就幾個方面分述如下:

\section{一 通過民客探樣, 是獲得硣量的最迅速最} 節省的勘探手段。地質撕探的最終目的，在於獲 得可以供給工業部門設計開採的缩量。篇了獲得 碳量, 我們可以利用槽探、井探、鑽探、坑探等

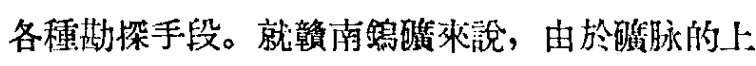
部多已被挖得殘缺不全, 要想了解磁脉上部的產 狀和品位變化，並配合鑽探和正規的坑探計算砤 量, 就必須進行廣泛的民蔡地質調笨和 探 樣工 作。一般說來, 上隆的探掘, 絕大部分是漫無規
則的。它的形狀千變萬化, 深淺宽深隨地而異, 安全設備也是絕無僅有。因此，民隆調朴工作是 此較困難和危險的。在工作的初期，我們由於對 通過民蔯探樣以獲得碳量的認識不矽, 對於上蔯 的調查工作, 曾琵足不前, 後隶, 經過蘇聯專家 的指導, 才深深學得通過民蕯探樣, 的確是獲得 础量的最迅速最節省的辦法。於是馬上大力原開

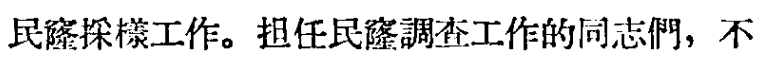
避歏苫, 不怕危險, 勇敢地、熱情地完成了任 務, 並初步取得了一些經驗。

二隨時整理原始資料, 進行線合研究, 編 㱔各種線合地翼圖表, 是提高業務水平, 指道工 作前進的必要方法。解放以前, 地質人员的一種 最壞的工作穹慣, 就是將長期野外工作所得的原 始資料, 總是留在野外工作結非国到空內以後才 進行整理。他們美其名日“室內研究”。通種把本 來是一個完整的地質勘探工作, 人第地械然分 䉆野外調查和室內研究兩部分, 㙷然是脫離賽際 的。表洦看來, 過去的所謂野外工作, 似乎是一 種與䨢際有密切聯系的。但事拄上, 這種工作 多半是不問效果的; 他們將一切原始资料掅晨下 來, 到野外工作結束以後才進行整理。這棰“年 終結貝長”的工作替惿，在一般老的地質工作者的 心目中, 已經是根深蒂固的了。我們以前的工作,

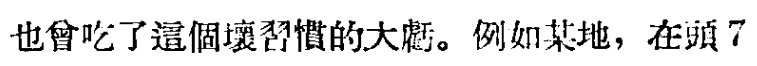
個月的工作中，對於一切原始紀錄，都没有進行 棕合菓編和統一整理。後來蘇聯尃家到山检岱和 指尊工作時，發現詐多資料都是界㣪分散的。那 時不但没有一張記錄各項工作進行及击完成情况 的勘探綜合圖, 就是連統一的圖例和㸤任世没有 
很好地加以規定。因此，槽探工作不能給鑽探設 計及時提供應有的資料; 鑽探工作也不能給坑探 指出前進的方向; 地表工作更不能給地下工作解 决問題。各部分的工作都是各自 窟政，孤立無 援。地質勘探工作中各個構成部分，本隶應該是 互相聯系互相補足的，但却人絾地變得支離破 碎，毫無生氣。狺樣，全體工作人員踓然簛風浴 雨，不避寒暑，在川上，在地下，堅持了工作大 牛年, 結果還是莫明其妙, 不知道究竟忙了一些什 空出來。他們的工作是目目的, 做了今天的工作 不知道明天做什尉。從而就降低了工作的熱情, 失却了工作的信心。後桃, 經畄了蘇聯專家的檢 查，指出了没有及時整理原始凟料和稂製出各種 綜合的地質圖表是勘探工作中最噘重的缺點 以 後, 我們才開始大力拝轉运種各自蘦政的渗散 局面，加强了整理资料的工作力量。在网個月時 間內，把從前所皘累下秝的原始紀錄，分别整理 後, 不但已經有了一張完整的茷探工作棕合圖, 而且還有一套完整的坑道地質圖，一套完整的試 料分俳圖，一套完整的岩心柱状圖，以及一晨完 整的礁量計算圖。這一套套的完整的綜合資料，

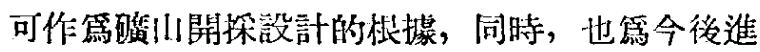
一步的地質勘探工作打下了一個䄳洞的基礎。從 此, 我們在彻探工作的進程中, 就能够做到心中

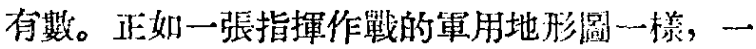

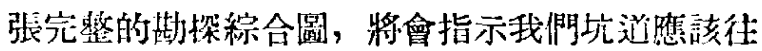

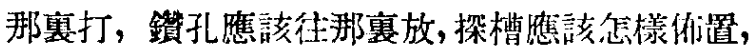
地質點的雚察應該在那裏進行。如果䋁現計劃有 不够逗密的地方，我們就可以及時修正它，同時， 工作人員能够眼看着自己的融劃得以逐 日逐月 的完成，也將鼓舞起繼續前進的信心和熱情。此 外, 坑道地質圖将會清晰地指出碳體的產狀及 其在成碳後的種種變化，便我們得以及時决定坑

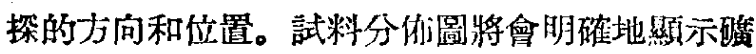
體的品位戀化情况，便我們得以及時修正探榜的

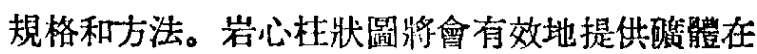

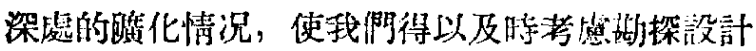

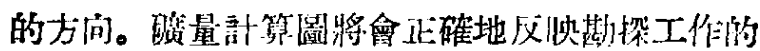
效果和深度，使浅們得以及時检杪整偑墈探工作 的目的性和潐確性。總之, 有了各種各愫的棕合

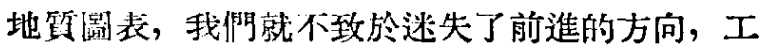
作效率也大䴇提高。
三 碳嵄的正確探取和加工，礦量的按時計 算和檢查，是搞好地票勘探工作的雨 個重要理 節。砤量是地質勘探成果的集中表現。在一定的 礁床地質條件下，如果地質勘探工作的深度恿大，

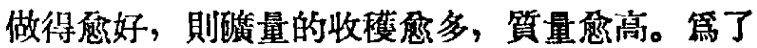
保證政量的數量和質量，必須保證試料工作的正 確和及時。我們在工作開始的時候，祭習了薢聯 關於酸量計算和試料探取的一些交件，踓然有了 一些感性知識, 但由於在過去的地質工作中，探 樣和酸量計算從來都不佔重要的位置; 大部分地 質人員對於這兩項工作在整個地質勘探工作中的 重要性，認識上是很模糊的。因此，對於蘇聯先 淮經驗的初步祭替，並没有能够立刻將這種由來

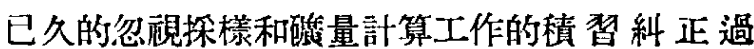
來。例如，各榢的戏術領導人員起初都毫無例外 地將工作重心放在地質點的佈置和觀察上，在地 層構造的研究上，或在其他地質問題的討論上。 這表現在:（1)在製訂作業計劃方面，試料計劃 往往過小，不合乎大量塯加碳量的要求。槽探往 徍不在主要的礁化帶佈置, 而且探槽完工以後, 又不及時探樣, 因此, 就不能結合地下坑道計算 盽量。民隆採樣工作做得不够，不能最迅速地最 節省地獲得䃘量。鑽孔的体置不是過於分散，便 是孔距太大，深度太深，不能配合地下坑道計算 $\mathrm{B}$ 級或 $\mathrm{C}_{1}$ 級的礁量。（2）在分配力量方而，往 征用紃驗最少、能力最弱的人員去担任探樣工 作。他們銷誤地認䉆，試料的探取和加工，只不 過是一回簡單而容易的施工管理工作，即使對於 地質碳床毫無知識的人，也是可以幹的。結果不 是試料溝的位置選摆得不對，便是探核的規格不 合乎規定; 不是試料在探取時丢失太大，便是在 探取前根本没有畫素描圖; 不是試料在加工時不 按照切喬特公式 $Q=k d^{2}$ 的正規手䌐淮行, 便是 没有按照正規的程序進行試料加工登記。追一切 都嚴電地影響了試料的代表性，也览重地影響了 的透量的可靠性。同時, 由於試料和础量工作抓得 不緊，整個勤探工作就失却了重心。無論地質點 做得多好多快，探槽地質圖做得多精緻，坑道地質 圖做得多完整,但一問到這些工作都是䉆了什麼， 它們的效果究竟如何, 便茫然不知所答, 也根本 没有具體的材料可以答得出來。這種情况，一直 到蘇聯專家給我們作了詳畫的检查和誠烈的畓助 


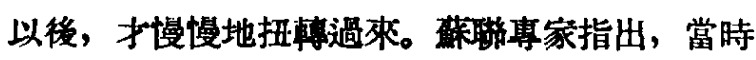
工作中最大的一個缺點, 就是試料計劃太小和試 料工作落後。蘇伤專家指出：一般的探樣工作， 對於機据坑道，不得落後於進尺 5 公尺; 對於手 掘坑道, 不得落後於進尺 2 公尺。岩心試料也須及 時探取。在蘇聯，試料探取是由最優秀的最可靠 的技工坥任，試料管理也是由最好的技政人員負 甹。試料加工的工地, 要收拾得和醫療間一樣地

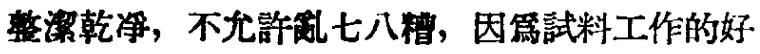
填, 直接影響㙏量的質和量。我們花了許多錢去 深取試料, 如果得不到正確的結果, 那不但是浪 费，而且是一種對國家不負責的錯誤行篇。

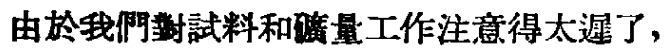
到年終大部分暖山的碃量結算, 還沒有徹底完成。

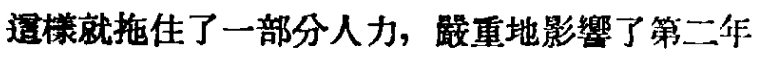
工作的全面展開。今後我們必須荛照蘇聯專家的 建議, 抓住試料和碳量選兩個重要環節, 在一切 都第了睡量的指導思想下, 加强試料的探取和加 工工作，以便確保試料的代表性和潐確性，蓝給 按時計算碑量提供必要的資料。

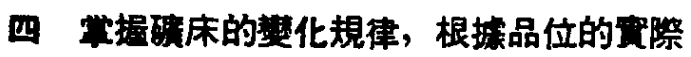

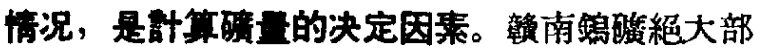

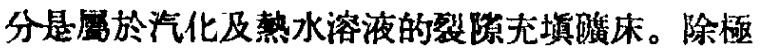
少數浸染睡體外, 它的形狀都是脉狀的。對於這

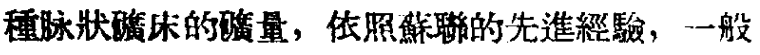
是根摄第三類睡床所要求的條件來計算的。但嫦

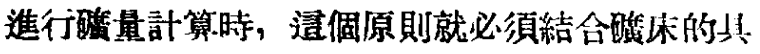
淔佟件和特徽隶露活運用。例如，我門起初計算 沿脉坑道的上下部分的醋量時, 曾粶機械地執行

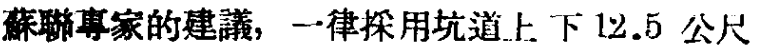

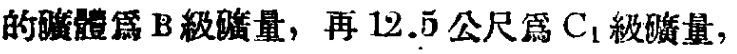
再 25 公个第 $\mathrm{C}_{2}$ 数睡量。後來, 經過了牛年的愺 探工作，對於各磺山睡脉的平均厚度和平均品位 都有了初步的資料, 㯰時, 另一位蘇聯專家到了韸 南, 他建議我椚沿脉坑道上下的 $\mathrm{C}_{1}$ 級鹤量, 叮以 計算 40-45 公尺。最近, 蘇聯專家检查了一些砤 量部算資料以後, 又建議某些沿脉坑道下部的 $\mathrm{C}_{1}$ 級略量，叮以計算 60-80 公尺。上面這個例子恰 好說明了在碳床的具體條件具體情况之下，蘇聯 高家露活地運用了第三類酸床計算醌量的原則, 而我們既数佟地機械地搬用它。在最初, 各個酰 山的稘脉情况和品位情况, 都只是估計的, 並没
有貫際的資料做根據，因此，磁量計算的力法， 只好樶據一般的原則來决症。後隶，我們初步学

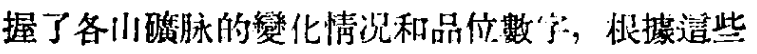

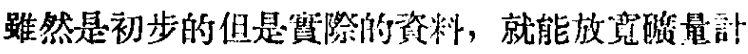
算的範園。最後, 由於检枮了每條硪脉的厚度和 品位,才選出了一些厚度十分稳定、品位比較均的 的碳脉，加大了它們的碳量計算範偉。由此可見，

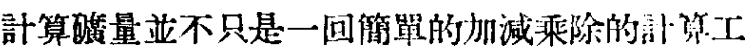
作, 它要求我們對於战床的變化規律和品位的密 際情况，都要有全面的了解和涊陚，然後好·去隨 時圈定那一條那一段的計算筈湋。㷳該注意的: 第了能够正確地掌探碳床的變化規律和品位的賽 際情况, 必須做好試料探取和加工的工作, 否 則, 試料就會失却了它的代表性, 睡冰的环確品 位就不會獲得，從而磁量計算的結果世就不叮靠。

五 有利的地翼構造條件，多次的成碳作

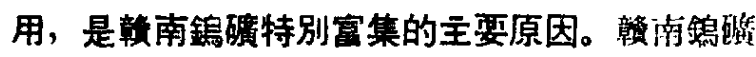

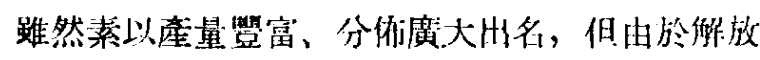

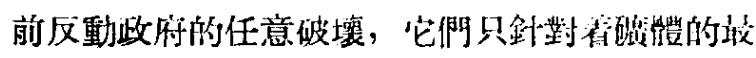

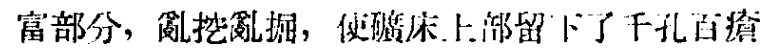

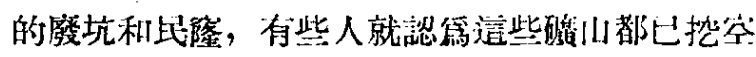

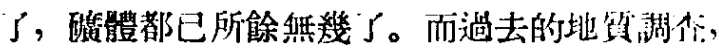
多牛都是走馬看花式帕探查和訪問性質，地貿人 員在一個础山的工作時間，多的不過十天八大，

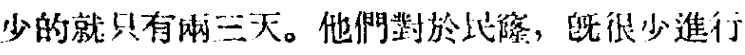

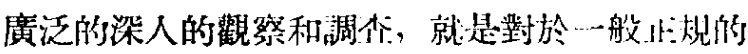
坑道，也很少有完整的系統的級錄。他們在到碳

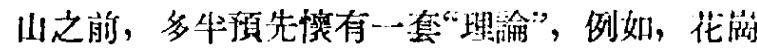
岩體中的䃑脉, 有用酸物的深度是不會很大的等

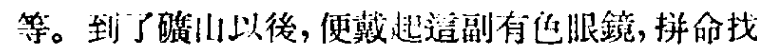

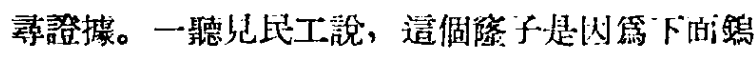

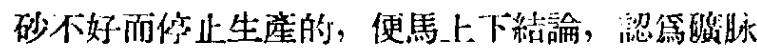
的有用部分不會超遥 80 公心。父有一些地 質人

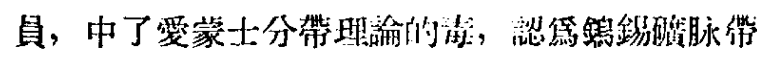

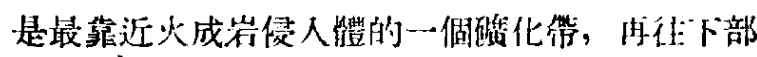

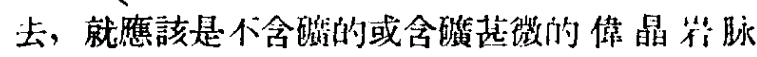
帶。因此，他們一旦看胃了較多的偉鼠茫脉露站，

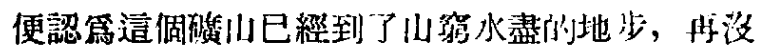

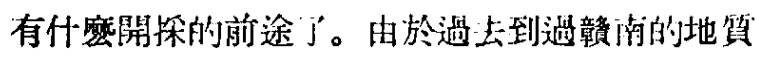
工作者, 帶着諸如此類的形形色色的唯心主皒的 觀點和“理論”，他們竞筧主觀地一个絬論近: “䫒

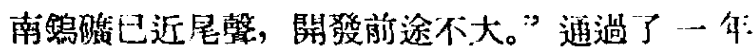


來的勘探工作，我椚目前所擁有的碛㕅资科，踓 然只是一些極不完全的和初步的資料，但是，根 據这些資料，我椚已經可以駁倒上面䑊些“結論”， 而且也可以批判愛蒙士分帶理論的機械論和唯心 喻的本質，證明蘇聯础休學者最近所發展起來的 一些先進理論的正確性。

過去, 䫓南鵭碾是以民蕯來開探的。如上所

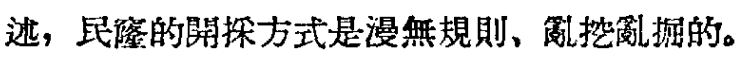
對於每一條本來是十分完整的䃫脉，他們任意 從左右上下, 零打碎敲, 探易不探難, 探富不探 負。遇到富睢體, 則争着揩掘, 遇到較貧磪體或 施工稍難之處, 則立即廢㯎, 另開新蕯。這種遊 牧式的開探方法, 使人們很難刵断鄀道的放集, 究竟是由於磂體挖完, 還是由於施工困醮。過去 地質人員看見廢限累累, 便輕易地認第䂗體已經 挖完, 下面再没有砾了, 䃘脉可探深度不會超過 80 公尺。事賎上，我們在幾個花岗岩體的厒山， 通過民隆調查的結果, 發現民蕯裹挽脉下部的品 位，一般都很好，可探深度也决不止幾十公尺。部 多民隆之所以被廢拿，完全是由於施工困灘或由 於富喽體已被挖空的線故。而且, 磪脉可探深度的 大小, 决不是簡單地决定於它距火成岩侵入體的 裳近, 或决定於它位於火成岩侵入體的上部抑下 部。更重要的條件是: 構造條件是否有利, 成睡 作用是一次的抑多次的，是順序漸進的抑往復淮 行的。

根譃初步的了解, 我們發現西華山酸區有先 後雨期的花崩岩侵入體。网者都具有强烈的碑化

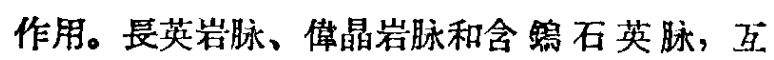
相割切的現象非常普遍。有不少後期的岩脉和像 脉, 都是沿着前期的岩脉和敂脉所充境的裂隐繼 湲侵入。長英岩和偉晶岩的侵入, 各有先後兩吹, 石英脉的生成, 也至少有三次。因此, 它們常常造 成了平行和重叠的構造。㯰就充分說明了西華山 區的碷化作用, 不是一次的, 而是多次的; 不是單 一的順序分化, 而是複篗的反復的碳化。同時, 由 於西華山花滆岩侵入體的破裂作用特別發澾, 两

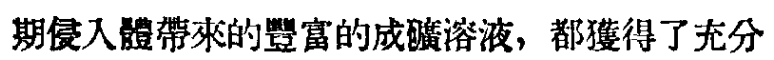

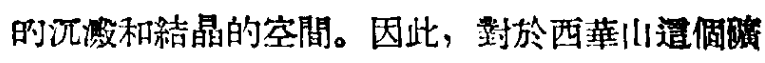
眿數以百計的規模宏大的鴊酸朱的生成, 我們决 不能搬用陳崔的一次瞚化的酷佅理論來解釋，而 須要根據更多的資料，針對着它本身的條件和特 點, 做出一個完整的結論來。

糡南其他鴊础區，也多因具有有利的構造條 件和多次的碳化作用, 因而造成很好的砤藏。

對於磞床的分帶問題, 根據我們的初步觀察,

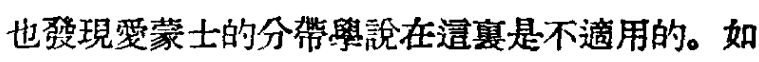
在某區，代表汽化高温性筫的嗒物，如鋰雲四、

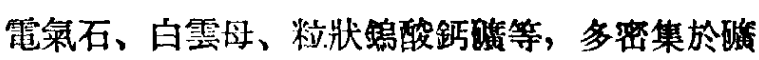

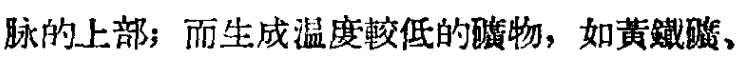

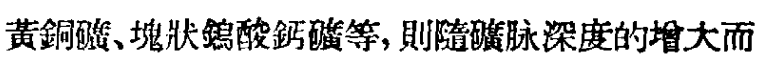
加多。其次, 汽化高温和中温的砋物常常混集一

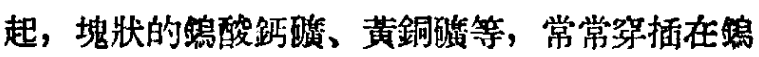

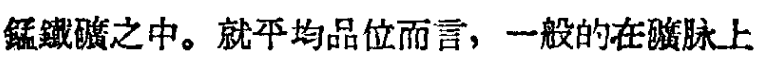
部較低, 在下部則較高。传就充分地說明, 如果低 照要蒙士的單一岩基分帶說或地熱分帶說, 對逐 區的成礁作用和次序是不能解釋的。反之, 如果 我們探用蘇聯關於碃朱分帶的先淮理論, 認篇一 個碳床的分帶現象, 决不是簡單地取决於地熱等 坡線的存在, 更重要的是决定於成碰溶液的間歇

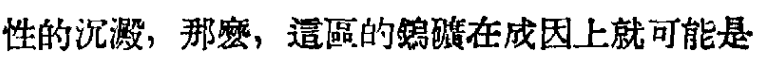
成於多次成礦的類型, 在分帶上是屬於逆问間歇 性分帶的類型。磞脉的上部代表汽化滈温熱液過 渡期, 往下則變第高温熱液期。有些部分, 則代表 各期的混集。如果這個結論可靠, 則造區住础的 可探深度是大狩希望的。

形形色色的資産階級的地質里說, 是充满着 主觀臆測的成分的。我椚必須提防它們的影響和 侵警, 努力地去掌握蘇聯的先進理諭, 賽事求是 地去搞好我們的工作。通過一年的工作和等, 我們深深地體會到穌聯先淮經驗不但在望践的效 果上遠遠地超過了資本主義國家, 而且在理論的 水平上也是大大地高出了資本主莪國家。䔉枷地 質學家研究與解决地質問題的方法, 是蘇聯科 學家常握與渾用馬克思列密主義的經驗的一個䇢 例。 